\title{
Novas espécies de Sundarion Kirkaldy (Hemiptera, Membracidae)
}

\author{
Antonio José Creão-Duarte', Olívia Evangelista de Souza² \& Rembrandt Romano A. D. Rothéa²
}

'Departamento de Sistemática e Ecologia, Universidade Federal da Paraíba. 83800-990 João Pessoa-PB, Brasil. creao@dse.ufpb.br ${ }^{2}$ Programa de Pós-Graduação, DSE-UFPB. 83800-990 João Pessoa-PB, Brasil.

\begin{abstract}
New species of Sundarion Kirkaldy (Hemiptera, Membracidae). Four new species of Sundarion Kirkaldy, 1904 are described and illustrated: S. compactum Souza \& Rothéa sp. nov., S. costaricense Souza \& Rothéa sp. nov., S. notabile Souza \& Rothéa sp. nov., and S. rubricatum Souza \& Rothéa sp. nov. The first two species are from Costa Rica, and two others from Brazil, Mato Grosso.
\end{abstract}

Keywords. Membracidae; new species; Sundarion; taxonomy.

Resumo. Novas espécies de Sundarion Kirkaldy (Hemiptera, Membracidae). Quatro novas espécies de Sundarion Kirkaldy, 1904 são descritas e ilustradas: S. compactum Souza \& Rothéa sp. nov., S. costaricense Souza \& Rothéa sp. nov., S. notabile Souza \& Rothéa sp. nov. e S. rubricatum Souza \& Rothéa sp. nov. As duas primeiras são da Costa Rica e as outras do Brasil, Mato Grosso.

Palavras-Chave. Membracidae; novas espécies; Sundarion; taxonomia.

Kirkaldy (1904) propôs o nome Sundarion em substituição a Pyranthe Stål, 1867 que estava pré-ocupado em Tettigonidae. McKamey (1998) catalogou para o gênero, nove espécies cuja distribuição se estende desde a América Central até à Argentina.

Neste trabalho, quatro novas espécies são propostas para Sundarion, duas da Costa Rica e duas do Brasil. O material examinado é oriundo das seguintes instituições: DZUP Departamento de Zoologia, Universidade Federal do Paraná, Curitiba-PR, Brasil; INBIO - Instituto Nacional de Biodiversidad, Santo Domingo, Heredia, Costa Rica.

\section{Sundarion compactum Souza \& Rothéa sp. nov.} Figs. 1, 5-7

Medidas (mm). Fêmea/macho. Comprimento do pronoto 7,69/7,13; comprimento total 8,87/7,92; largura da cabeça 3,64/ 3,72 ; altura da cabeça $1,74 / 1,58$; distância entre os processos supra-umerais 5,55/5,23; altura dos processos supra-umerais $1,98 / 1,98$.

Diagnose. Processos supra-umerais pontiagudos, tetracarenados, curtos, menores que a metade da distância entre suas bases, enegrecidos para as extremidades. Lóbulos pós-oculares arredondados. Processo posterior afilado abruptamente nas proximidades do ápice.

Holótipo macho. Cabeça amarela, lisa, com discretas pontuações limitadas aos lóbulos supra-antenais. Sutura epistomal interrompida no limite do pós-clípeo com a fronte. Sutura coronal limitada ao vértice. Ocelos eqüidistantes entre si e dos olhos. Margem inferior do pós-clípeo angulosa, se estendendo muito além da margem interna dos lóbulos supraantenais; estes laminados e projetados para baixo, estreitandose em direção aos olhos. Pronoto castanho-amarelado, com pontuações finas e escurecidas nas adjacências dos processos supra-umerais e metopídio; região lateral com uma área de depressão de contorno sinuoso e bem definido. Processos supra-umerais curtos, pontiagudos, tetracarenados, defletidos para cima e para os lados. Lóbulos pós-oculares estreitos, arredondados. Carena mediana definida, porém menos acentuada na porção central, declinando suavemente até à extremidade. Processo posterior afilado abruptamente a partir do terço apical, terminando pouco antes do final da $\mathrm{M}_{3+4}$, com extremidade preta. Tégminas hialinas com veias bem definidas; com um escurecimento castanho ocupando grande parte da primeira e segunda células apicais e, também, a discoidal externa. Pernas castanhas com as coxas e superfície dorsal dos fêmures ligeiramente mais escuras. Mesepisterno, mesepimero e uroesternitos castanho-amarelados. Edeago em forma de U com ápice em forma de disco, com espinhos em seu contorno. Placa subgenital curta, não excedendo em duas vezes a sua largura.

Fêmea. Semelhante ao macho, ligeiramente maior.

Holótipo macho de "COSTA RICA, Prov. Limon. Sector Cerro Cocori, Fca./ de E. Rojas 150 m, Prov./ Limon, Costa Rica, F. A./ Quesada, 26 mar a 24 abr/ 1991, L-N 286000, 567500" (INBIO). Parátipos: 1 macho, "COSTA RICA, Sirena, Corcovado Nat./ Pk., OsaTenin. 19-27 Mar 1981/ DH Janzen \& W. Hallwachs" (INBIO); 1 macho, "COSTA RICA, Sector Cedrales de la Rita, Prov./ Limón. 10 m set 1995./ E. Rojas, L_N_278600_566500\#6123” (INBIO). 1 macho, "COSTA RICA, Prov. Limón, Sector Cerro/ Cocori, $30 \mathrm{Km} \mathrm{N}$ de Cariari, 100m., 18/Nov 1994, 286000_567500 L_N, E. Rojas/ \#4135” (INBIO). 1 fêmea, "COSTA RICA, Prov. Puntarenas,/ Send. El Ripário a $3 \mathrm{Km}$ NE. De/ Progreso. 1300 m. 6-9 May 1997./E. Navarro. De Luz/ L_S_319000_597000 \#46280" (INBIO).

Comentários. Esta espécie distingue-se das demais pelos processos supra-umerais relativamente curtos, tetracarenados e enegrecidos apicalmente. 

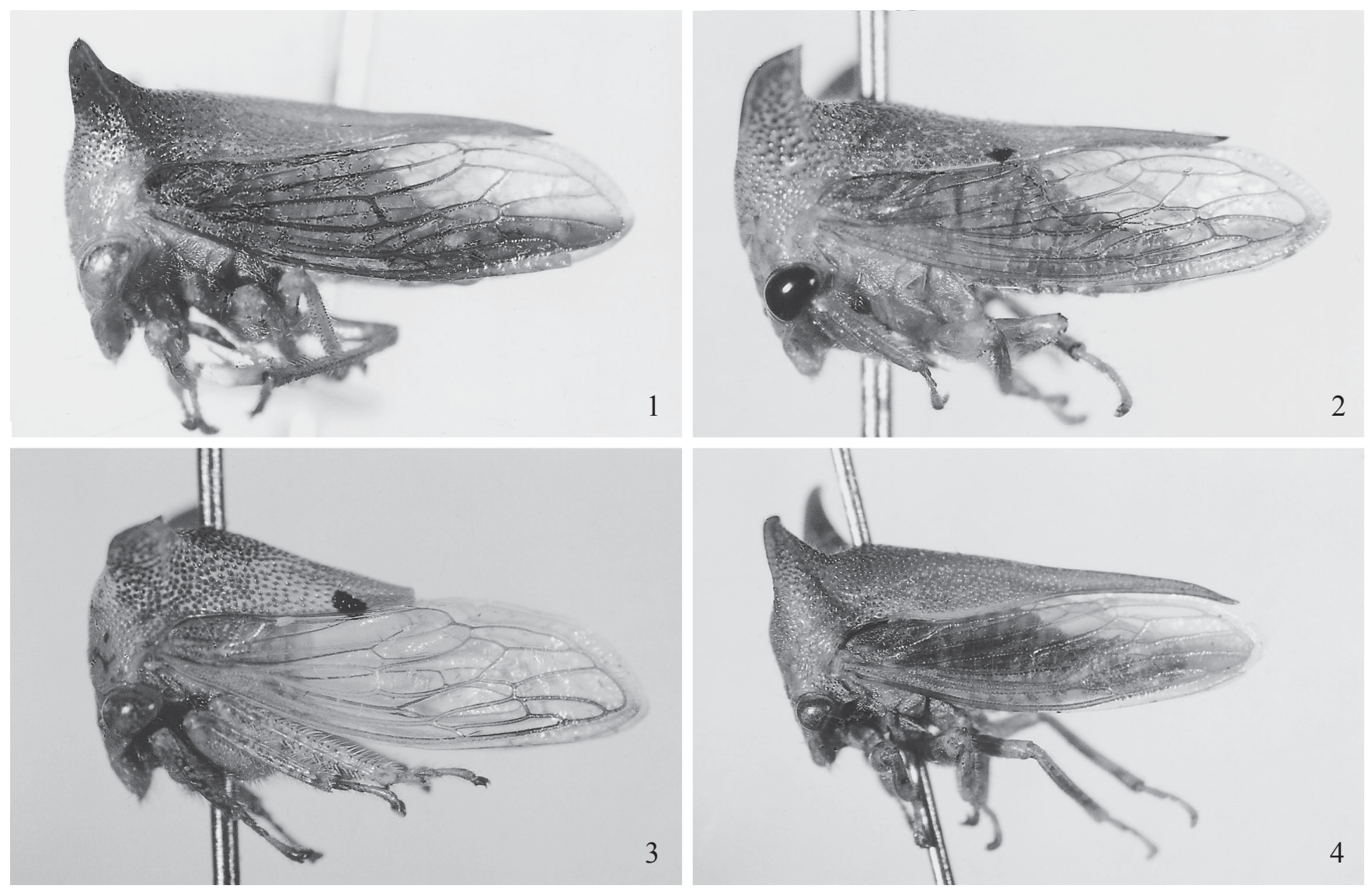

Figs. 1-4. Espécies de Sundarion Kirkaldy: 1, S. compactum Souza \& Rothéa sp. nov. (holótipo); 2, S. costaricense Souza \& Rothéa sp. nov. (holótipo); 3, S. notabile Souza \& Rothéa sp. nov. (holótipo); 4, S. rubricatum Souza \& Rothéa sp. nov. (holótipo).

\section{Sundarion costaricense Souza \& Rothéa sp. nov.}

Figs. 2, 8-10

Medidas (mm). Fêmea/macho. Comprimento do pronoto $8,75 / 7,62 ;$ comprimento total $10,0 / 8,87$; largura da cabeça $4,37 /$ 3,87 ; altura da cabeça $1,62 / 1,49$; distância entre os processos supra-umerais 7,87/6,37.

Diagnose. Pronoto castanho-amarelado, com pontuações mais ou menos grossas, escuras, e com uma pequena mancha preta de cada lado, junto às margens laterais. Processos supraumerais bem desenvolvidos, espatulados, tricarenados, dirigidos para cima e para os lados, e com o ápice ligeiramente voltado para trás. Edeago em forma de $\mathrm{U}$, com três carenas transversais entre a falobase e o edeago propriamente dito; globoso apicalmente, com espinhos dispersos na face interna.

Holótipo macho. Cabeça castanho-amarelada. Sutura coronal e epistomal indefinidas. Ocelos mais próximos entre si do que dos olhos. Margem inferior do pós-clípeo estendendose além da margem interna dos lobos supra antenais, laminados e projetados para baixo, estreitando-se em direção aos olhos. Pronoto castanho-amarelado com pontuações mais ou menos grossas e bem definidas, apresentando discretas manchas amarelas, mais adensadas sobre o metopídio; região lateral com uma área de depressão de contorno sinuoso, tendo uma pequena mancha escura semicircular junto à margem lateral. Processos supra-umerais bem desenvolvidos, com pontuações escuras, espatulados, tricarenados, dirigidos para cima e para os lados, e o ápice voltado para trás. Lóbulos pósoculares pontiagudos e dirigidos para trás. Carena mediana bem definida. Processo posterior afilado abruptamente a partir do terço apical, terminando pouco antes do final da $\mathrm{M}_{3+4}$, com ápice preto. Tégminas hialinas, com veias bem definidas, apresentando um escurecimento castanho-translúcido, muito discreto, preenchendo a segunda célula apical. Superfície inferior do tórax, pernas e abdome castanho-amarelados. Edeago em forma de $\mathrm{U}$, com três carenas transversais entre a falobase e o edeago propriamente dito; globoso apicalmente, com espinhos dispersos na face interna. Placa lateral do pigóforo globosa na extremidade. Placa subgenital com o seu comprimento não alcançando uma vez e meia a sua largura basal.

Fêmea. Semelhante ao macho; um pouco maior.

Holótipo macho de “Amubri, Prov. Limón, COSTA RICA. 70 m./ 12-31 Oct 1993, G. M. Gallardo,/ L S $385500 \_578000$ \#2407” (INBIO). Parátipos: 1 fêmea, “Amubri, Prov. Limón, COSTA RICA. 70 m./ 08- 


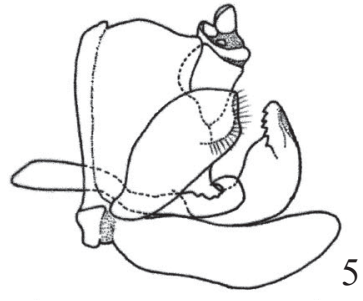

$1,0 \mathrm{~mm}$

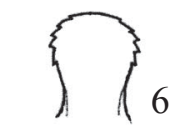

$0,5 \mathrm{~mm}$

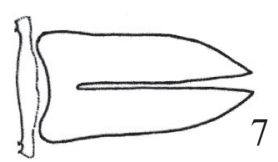

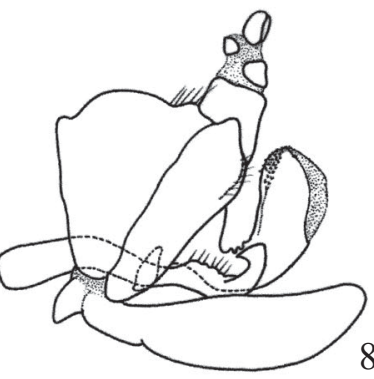
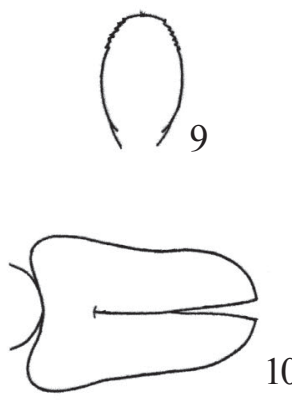
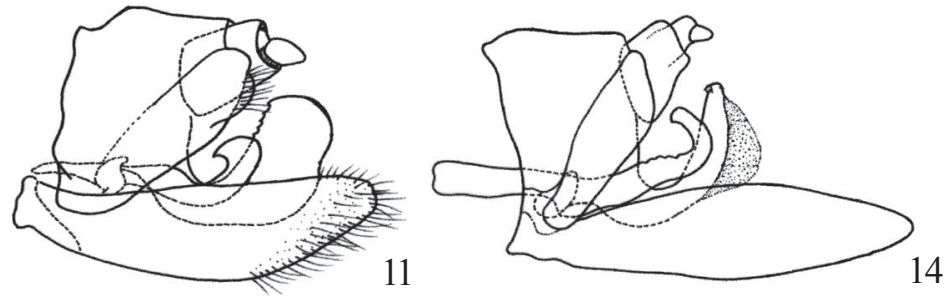

12

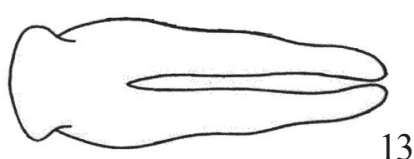

13

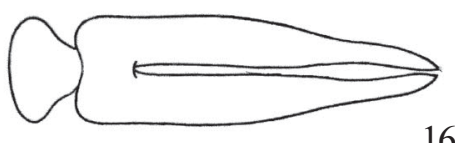

Figs. 5-16. Genitália (vista geral, lateral; detalhe do ápice do edeago; placa subgenital): 5-7, Sundarion compactum Souza \& Rothéa sp. nov.; 810, S. costaricense Souza \& Rothéa sp. nov.; 11-13, S. notabile Souza \& Rothéa sp. nov.; 14-16, S. rubricatum Souza \& Rothéa sp. nov.

27 nov 1993, G. M. Gallardo, L S / 385500_578000 \#2461” (INBIO); 1 macho, "Amubri, Prov. Limón, COSTA RICA./ 70 m. 1-22 ENE 1995. G. Gallardo,/ L S 385500_578100 \#4388" (INBIO); 1 macho, "Amubri, Prov. Limón, COSTA RICA. 70 m./ 1-29 AGO 1994, G. M. Gallardo, L S / 385500578000 \#3178" (INBIO); 1 macho, "Monumento Nacional Guayabo, Turrialba,/ Prov. Carta COSTA RICA. 1100 m. Set/ 1994, G. Fonseca, L N 217200_570300/ \#3202" (INBIO); 1 fêmea, "COSTA RICA. Prov. Limón. Est Águas/ Frias. 10-20 m. OCT 1997. E. Rojas./ Red de Golpe/ L N 264700580300 \#48089" (INBIO); 1 fêmea, "COSTA RICA, Prov. Limón, Est./ Águas Frias. 1020 m. SET 1997./ E. Rojas. De Luz/ L N 264700580300 \#47715" (INBIO); 1 fêmea, "Playuelas, 20 m, Caño Negro,/ RNVS Caño Negro , Prov. Alaju.,/COSTA RICA. 19 a 31 dic 1992. K./ Martinez. L-N325900, 454500" (INBIO); 1 macho, "Turrialba, Costa Rica/ 600 m/ 10.X.1971/ V. O. Becker col." (DZUP); 1 macho, "Turrialba/ Costa Rica/ 10.XI.1971/ V. O. Becker" (DZUP). 1 macho, "Turrialba, Costa Rica/ 600 m/ 10.X.1971/ V. O. Becker col.” (DZUP).

Comentários. Esta espécie é muito parecida com S. flavum (Fairmaire, 1846) no seu aspecto geral. Diferencia-se principalmente pelas pontuações mais grossas do pronoto e pelos detalhes da genitália.

\section{Sundarion notabile Souza \& Rothéa sp. nov.} Figs. 3, 11-13

Medidas (mm). Macho. Comprimento total 8,08; largura da cabeça 3,72; altura da cabeça 1,58; distância entre os processos supra-umerais 5,15 .

Diagnose. Processos supra-umerais castanhoavermelhados, curtos, espatulados, tricarenados, dirigidos para os lados e discretamente voltados para cima, elevandose muito pouco acima do nível médio do pronoto. Tégminas hialinas, imaculadas, com veias bem definidas.

Holótipo macho. Cabeça amarela, lisa, com área de depressão em torno dos ocelos. Sutura epistomal bem definida, a coronal junto ao vértice. Ocelos mais próximos entre si do que dos olhos. Margem inferior do pós-clípeo estendendo-se muito além da margem interna dos lóbulos supra-antenais; estes laminados e projetados para baixo, estreitando-se em direção aos olhos. Pronoto amarelado, com a porção mediana vermelho-ferruginosa, incluindo os processos supra-umerais; região lateral com uma área de depressão de contorno sinuoso $\mathrm{e}$, aproximadamente no meio, junto às margens laterias, a cada lado, uma mancha preta, ovalada, disposta obliquamente. Processos supra-umerais castanho-avermelhados; curtos, espatulados, tricarenados, dirigidos para os lados e discretamente voltados para cima, com o ápice voltado para trás, elevando-se muito pouco acima do nível médio do pronoto. Carena mediana bem definida. Tégminas hialinas, com veias bem definidas e sem escurecimento distal. Pernas castanhas com as coxas e superfície dorsal dos fêmures ligeiramente mais escuras; superfície externa das tíbias com manchas circulares amarelas. Mesepisterno castanho. Mesepimero e uroesternitos castanho-amarelados. Edeago em forma de $\mathrm{U}$, fortemente intumescido, com ápice globoso tendo na superfície interna inúmeros espinhos.

Fêmea. Desconhecida. 
Holótipo macho de "SINOP-M[ato]. Grosso/ Brasil- X/1975/ M. Alvarenga" (DZUP).

Comentários. Espécie semelhante à anterior. Difere no colorido geral do pronoto, no qual se salientam pontuações mais ou menos grossas e avermelhadas. Os processos supraumerais são achatados dorso-ventralmente e, em vista superior, com as margens subparalelas, obliquamente truncados no ápice e com o ângulo posterior agudo. A mancha preta lateral é bem maior.

O holótipo está com parte do processo posterior quebrado, logo depois da mancha preta lateral.

\section{Sundarion rubricatum Souza \& Rothéa sp. nov. Figs. 4, 14-16}

Medidas (mm). Fêmea/macho. Comprimento do pronoto $10,87 / 9,75$; comprimento total $11,12 / 10.25$; largura da cabeça 4,50/4,12; altura da cabeça $1,87 / 1,52$; distância entre os processos supra-umerais $7,5 / 6,37$; altura dos processos supraumerais: 4,0/3,25

Diagnose. Processos supra-umerais alongados, fortemente afilados para o ápice, tricarenados, castanho-avermelhados dorsalmente e, ventralmente, com uma faixa vermelha que se estende do ápice em direção ao ângulo umeral.

Holótipo macho. Cabeça amarela, com áreas de depressão em torno dos ocelos, entre o pós-clípeo e a fronte e sobre os lóbulos supra-antenais. Ocelos mais próximos entre si do que dos olhos. Sutura epistomal bem definida, a coronal apenas no vértice. Margem inferior do pós-clípeo estendendo-se muito além da margem interna dos lóbulos supra-antenais; estes laminados e projetados para baixo, estreitando-se em direção aos olhos. Pronoto amarelado com pontuações distintas; região lateral com uma área de depressão de contorno sinuoso entre a carena mediana e a margem. Processos supra-umerais mais ou menos longos, fortemente afilados distalmente, tricarenados, castanho-avermelhados dorsalmente, tendo na superfície ventral uma faixa vermelha estendida desde o ápice até próximo do ângulo umeral, acompanhando a carena lateral. Lóbulos pós-oculares pontiagudos e projetados para trás. Carena mediana bem definida em toda sua extensão, declinando suavemente até a extremidade do pronoto. Processo posterior afilado abruptamente a partir do terço apical, terminando quase no final da $\mathrm{M}_{1+2}$. Tégminas hialinas com veias bem definidas e um enfumaçamento marrom-claro na altura da segunda e terceira células apicais. Pernas amareladas com a coxa mediana e superfície dorsal dos fêmures ligeiramente mais escurecidas. Mesepisterno castanho, mesepimero e uroesternitos amarelos. Edeago em forma de U, com discreta projeção lateral. Parâmeros bem desenvolvidos com a superfície interna provida de ranhuras. Placa subgenital relativamente longa, cerca de três vezes a sua largura basal.

Fêmea. Semelhante ao macho, porém, um pouco maior.

Holótipo macho de "SINOP-M[ato]. Grosso/ Brasil - X.1975/ M. Alvarenga" (DZUP). Parátipos: 3 fêmeas, ibidem (DZUP); 1 fêmea e 1 macho, ibidem (DSE/UFPB).

Comentários. Esta espécie se destaca das outras pelos processos supra-umerais alongados e visivelmente delgados para o ápice, de coloração avermelhada; em vista lateral, são ligeiramente voltados para frente. O processo posterior é longo, quase atingindo o ápice das tégminas.

Agradecimentos. À Dra. Carolina Godoy (INBIO) pelo envio dos espécimes para estudo.

\section{REFERÊNCIAS}

Kirkaldy, G. W. 1904. Bibliographical and nomenclatorial notes on the Hemiptera $-n^{\circ}$ 3. The Entomologist 37: 279-283.

McKamey, S. H. 1998. Taxonomic Catalogue of the Membracoidea (Exclusive of Leafhoppers) - Sencond suplement to Fascicle 1 Membracidae of the General Catalogue of the Hemiptera. Memoirs of the American Entomological Institute 60: $377 \mathrm{pp}$. 